\title{
Choices from Identical Options in a Virtual Shopping Aisle
}

\author{
Daniele Porcheddu ${ }^{*}, 1$ and Alberto Venturi ${ }^{2}$ \\ ${ }^{I}$ Department of Economics, Business and Regulation, University of Sassari, Sassari, Italy \\ ${ }^{2}$ Electronic and Electrical Engineering Department, Strathclyde University, Glasgow, Scotland, UK
}

\begin{abstract}
Through an experiment in a virtual environment, in this work we studied the relationship between vertical and horizontal shelf location and the frequency with which shoppers select items. We tested a random distribution hypothesis of the picking up frequencies (PUFs) in relationship to item shelf position within an experimental framework with various constant hypothesized confounding variables. The equidistribution hypothesis was rejected in a test with 600 virtual shoppers, providing evidence for the existence of a gravitational force towards certain shelf locations. In particular, the PUFs resulted significantly higher for eye-level and waist-level locations when items were placed in the first half of the virtual gondola. On a theoretical level, our experiment also shows that the minimal physical effort principle is probably not a good explanation for the qualitative heterogeneity of shelf space and for the associated shelf position effects. Limitations and managerial implications of our work were also discussed.
\end{abstract}

Keywords: Merchandising, quality of shelf space, shelf position effects, minimal-physical effort principle, picking-up frequencies, virtual aisle.

\section{INTRODUCTION}

Research in the field of qualitative heterogeneity of shelfspace reported in the international literature is relatively scarce. The situation with regard to studies devoted to the problem of shelf space allocation is quite different, as there is a significant amount of literature on this topic [1-4].

In spite of the relative scarcity of scientific studies on the subject, many managers continue to hold on to widespread and stubborn beliefs about the desirability of some shelf locations both along the vertical and horizontal dimensions. In fact, certain rules of thumb regarding shelf position are routinely applied in the business environment [2, 5-7]. Hubbard [8] states that retailers and manufacturers traditionally hold the widespread opinion that eye-level is the most effective location for the display of a product. Unfortunately, it is less clear what is actually meant by eyelevel on a shelf: "Retailers and manufacturers believe that brand location has an important impact on sales. Eye-level often is seen as the best location. However, when pressed to be more specific about what is meant by eye-level, we found that experts were referring to any one of several shelves above the knees but below $61 / 2$ feet" [5, p.312]. Moreover, there are also conflicting opinions with regard to the horizontal quality of the shelf space: "Manufacturers also profess preferences for particular positions along the horizontal plane. Some believe the middle is the focal position, but others prefer the edges in order to be first or last in the planogram" $[5, \mathrm{p} .312]$.

Furthermore, the study by d'Amico et al., [6] demonstrated the existence of a shelf placement mythology

\footnotetext{
*Address correspondence to this author at the Department of Economics, Business and Regulation, University of Sassari, via Muroni, 25, 07100, Sassari, Italy; Tel: +39.79213024; Fax: +39.79213002;

E-mail: daniele@uniss.it
}

that strongly influences managers in spite of empirical evidence indicating that these beliefs are unfounded. The same authors observe that: "The longevity of shelf placement 'rules of thumb' is not a certain affirmation of their veracity, nor is their value proven by the fact that they are logical" [6, p.14].

A list of existing rules of thumb in the practice of merchandising is set out in the work of Phillips and Bradshaw [7, p.58], who also recall the process of trial and error through which these rules are formed.

The main aim of this study is to investigate, through an experiment in a virtual environment, the link between the vertical and horizontal shelf position of items and the frequency with which shoppers pick up said items. We emphasize that our experiment is designed to measure the effects of positioning only in terms of the likelihood of shoppers picking up items and not of subsequent sales or profit. As Masson and Wellhoff [9, p.89] write: "The better known rule of merchandising is: not seen not taken, not taken not sold", so picking up is only a necessary step towards the next stages of a process that can lead to (obviously in a non-deterministic way) the purchase of the given item.

This paper is organized as follows: Section 2 provides a brief survey of the literature on the heterogeneity of shelf space and associated shelf location effects; Section 3 identifies knowledge gaps that our study attempts to fill; Section 4 outlines the confounding variables problem and the usefulness of computer-mediated experiments in the field of consumer research. In Section 5, we propose a working hypothesis on shelf position effects and in Section 6 we discuss the testing process in a virtual laboratory experiment. Section 7 is devoted to presenting our experiment's results, while Section 8 presents a discussion of said results in light of our research objectives. We conclude our article with a 
discussion of the study's limitations (Section 9) and managerial implications of obtained results (Section 10).

\section{HETEROGENEITY OF SHELF-SPACE AND ASSO- CIATED SHELF POSITION EFFECTS: A SURVEY OF THE LITERATURE}

Studies concerned with the heterogeneity of shelf space are largely focused on an analysis of so-called shelf position effects.

First, what is a shelf position effect? Drèze et al., [5] suggest that it can be defined as the effect that changes in shelf location of a product category or individual brand have on sales, profits, or other dependent variables. These effects are the result of shifting items to qualitatively different shelf positions. In a sense, shelf position effects are an expression of the qualitative heterogeneity of shelf space.

We do not believe that a meta-analysis of the literature on shelf position effects would have proven useful in light of the heterogeneity of the studies in terms of nature, independent and dependent variables, and so forth. The review that follows is qualitative and includes academic studies (with the exception of the Colonial Study $[10,11]$ ) that deal with the phenomenon of shelf space quality in the context of traditional grocery stores. We therefore excluded all studies concerned with shelf position effects in the context of online shopping [12]. In addition, we only took into account studies that focus on the quality of shelf space in the context of regular grocery shelving. Therefore, works on the shelf position effect in special displays were not reviewed [13]. Studies that adopted an inter-type approach (i.e., that compared how different types of display - regular versus special - impact sales or other dependent variables) were also excluded from our literature review [14-16].

In short, works on shelf space quality can be grouped into three main theoretical paradigms.

The first paradigm focuses on theoretical models such as attention-based theory, which suggests that some shelf positions are more visually salient, attract more attention than others, and are therefore more likely to be chosen [2, 5, $8,17,18])^{1}$.

The second theoretical paradigm is based upon the minimal-effort principle. According to this principle, some shelf positions are better because they address the need of clients/observers/actors to minimize their effort during choice-making. This paradigm can be further broken down into two categories of models. Some authors refer to the minimal-mental effort principle, according to which picking up items located in certain shelf positions may require less concentration and might therefore be favored by shoppers [20]. Other studies, however, refer to a minimal-physical effort principle, according to which some shelf positions, such as top or floor level, are penalized because reaching them requires more physical effort by consumers $[10,11]$.

The third family of reference models can be termed belief-based. They suggest that clients/observers/actors share certain beliefs about shelf positions. These models are also

\footnotetext{
1 "Salience is defined as the aspect of a stimulus that makes it stand apart from other stimuli due to its inherent characteristics or its context" [19, p.186].
}

called inference-based since they highlight that subjects make inferences about products (in terms of price, quality, etc.) based upon their particular position on a shelf. These theoretical models reflect a number of recent studies concerned with shelf-space quality [19, 21, 22].

Table 1 summarizes the main aspects of the works examined in our review: Column 1) author(s) and year of publication, Column 2) the nature of the study, Column 3) the shelf position effect(s) examined, Column 4) results of the study, in terms of existence and strength/weakness of the effect(s) examined and identification of the potentially most desirable shelf positions; Column 5) theoretical paradigm of reference.

The intensity of the shelf position effect(s) presented in Table 1 reflects the opinion (unfortunately not always based on elasticity coefficients directly comparable) formulated by the authors of the various contributions.

It should be noted that most of the reviewed works focused exclusively on verifying the existence and magnitude of the vertical shelf position effect (VSPE). Few others limited their attention to the possible existence of the horizontal shelf position effect (HSPE). Rarely, the authors tested the presence of both effects separately (VSPE+HSPE). Finally, only the study by Drèze et al., [5] examined the interaction of the two effects (VSPE $\times$ HSPE).

Overall, the above-discussed review of the literature on shelf position effects leads us to argue that: 1) there is a certain convergence of results with regard to the existence and intensity of VSPE and the most desirable vertical locations, which are generally found at eye-level and/or midshelf; 2) there is more variability in studies with regard to the existence and intensity of HSPE and the location of the most desirable horizontal position (some research indeed indicates it corresponds to the edges of the shelf, but more numerous studies report a preference for the central horizontal position); 3) the considerable variability of results obtained from previous studies can probably be explained by uncontrolled confounding variables affecting point-of-sale dynamics in some of the studies cited in Table $\mathbf{1}[13,23]$; 4) a large portion of reviewed studies can be linked to attentionbased type models, while more recent studies often refer to more belief-based models; unfortunately, however, to our knowledge there are no studies that specifically refute the validity of the minimal effort paradigm, be it physical or mental.

\section{OBJECTIVES OF THIS STUDY}

In the above-discussed points, numbers 3 and 4 also highlight the knowledge gaps that our study endeavors to fill. Specifically, we have attempted to make two main contributions to research in this field. First, we assessed the existence and magnitude of shelf-position effects through a shopping experiment in a virtual environment that enabled us to control or reduce the effects of wide range of possible confounding variables. This was done in an effort to neutralize the possible distortions that these variables can exercise on the cause-effect relationship between the items' shelf position (independent variable) and the items' pickingup frequencies (dependent variable). Second, we were interested in utilizing the aforementioned computer-mediated 
Table 1. Synoptic Review of the Literature on Shelf Position Effects

\begin{tabular}{|c|c|c|c|c|}
\hline Author(s) (Year) & Nature of the Study & Effect(s) Studied & Results & Theoretical Model(s) \\
\hline $\begin{array}{l}\text { Colonial Study }[10 \\
11]\end{array}$ & Field Experiment & VSPE & Strong VSPE (best shelf position = eye-level) & $\begin{array}{l}\text { Minimal-physical effort model } \\
\text { and Attention-based model }\end{array}$ \\
\hline Hubbard [8] & Observational study & VSPE & $\begin{array}{l}\text { Strong VSPE (deducible only indirectly) (best } \\
\text { position = eye-level) }\end{array}$ & Attention-based model \\
\hline $\begin{array}{c}\text { Frank and Massy } \\
{[23]}\end{array}$ & Observational study & VSPE & Negligible VSPE & Not clearly deducible \\
\hline $\begin{array}{l}\text { Folwell and Moberg } \\
{[18]}\end{array}$ & Observational study & VSPE & $\begin{array}{l}\text { VSPE store and subcategory contingent (generally } \\
\text { most desirable positions = mid-shelf and eye-level } \\
\text { shelf) }\end{array}$ & Attention-based model \\
\hline Drèze et al., [5] & Field experiment & $\begin{array}{l}\text { VSPE+HSPE, } \\
\text { VSPE } \times \text { HSPE }\end{array}$ & $\begin{array}{l}\text { Strong VSPE (best shelf location = eye-level); weak } \\
\text { and category contingent HSPE; strong VSPE } \times \text { HSPE }\end{array}$ & Attention-based model \\
\hline Christenfeld [20] & Observational study & VSPE & Strong VSPE (vertical centrality preference) & Minimal-mental effort model \\
\hline Chung et al., [17] & Field experiment & VSPE+HSPE & $\begin{array}{l}\text { Strong VSPE (best shelf position = eye-level), HSPE } \\
\text { weaker (best position = edge-locations, in particular } \\
\text { the end of the shelf); results were format-dependent }\end{array}$ & Attention-based model \\
\hline Nierop et al., [2] & Field experiment & VSPE+HSPE & $\begin{array}{c}\text { Strong VSPE (best shelf location }=\text { eye-level), HSPE } \\
\text { weaker (most desirable position }=\text { beginning of the } \\
\text { shelf })\end{array}$ & Attention-based model \\
\hline Chandon et al., [21] & $\begin{array}{l}\text { Laboratory } \\
\text { experiment }\end{array}$ & VSPE+HSPE & $\begin{array}{l}\text { VSPE revealed (best locations = generally, middle- } \\
\text { top shelf), HSPE revealed (best position = center of } \\
\text { the shelf); results were partially outcome-dependent }\end{array}$ & $\begin{array}{l}\text { Attention-based model and } \\
\text { Belief-based model }\end{array}$ \\
\hline $\begin{array}{l}\text { Valenzuela and } \\
\text { Raghubir }[22,24]\end{array}$ & $\begin{array}{l}\text { Laboratory } \\
\text { experiment }\end{array}$ & VSPE+HSPE & $\begin{array}{l}\text { VSPE and HSPE revealed (centrality preference on } \\
\text { both the vertical and horizontal dimension) }\end{array}$ & Belief-based model \\
\hline $\begin{array}{l}\text { Valenzuela and } \\
\text { Raghubir [19] }\end{array}$ & $\begin{array}{l}\text { Laboratory } \\
\text { experiment }\end{array}$ & HSPE & HSPE revealed (centrality preference) & Belief-based model \\
\hline
\end{tabular}

experiment in order to test the robustness of the theoretical paradigm that emphasizes the minimal-effort principle as the chief explanation for the qualitative heterogeneity of shelfspace. Specifically, we focused on minimal-physical effort Theory. Though often cited in research as one of three main applicable theoretical paradigms, this theory does not appear to have been explicitly refuted in the literature but has instead received waning attention in more recent studies.

\section{THE CONFOUNDING VARIABLES PROBLEM AND THE USEFULNESS OF COMPUTER-MEDI- ATED EXPERIMENTS IN CONSUMER RESEARCH}

Some authors have pointed out that an analysis of shelf position effects may be influenced by the presence of numerous confounding variables [23] or interfering variables [13]. In order to deal with problems of this nature, over the past three decades several experiments in the field of consumer research have been conducted in computer-simulated environments. Computerbased experiments allow researchers to gather large amounts of data with a reduced expenditure of time and money and in a discreet manner [3, 6, 25-28].

Several authors have tackled the problem of generalizability or external validity of results obtained through laboratory tests by assessing, through different strategies, the bias arising from differences between physically real stores and more or less sophisticated virtual ones [25, 26, 29-33].

Several studies suggest that experiments conducted in a virtual environment can offer important insights into actual dynamic purchase behavior and have good predictive ability with respect to phenomena that actually occur within a real store $[25,26,29]$.

\section{HYPOTHESIS}

We formulated a hypothesis to be tested in a computersimulated shopping experiment.

Within an experimental framework that controls the effects of the major confounding variables in the examined behavioral situation, and in which, although some physical constraints are integrated into the simulation ${ }^{2}$, there is no physical effort connected to moving down the aisle and picking up items:

H1: We expect to observe a random distribution of item picking up frequencies regardless of their shelf location.

The former should be seen primarily as a working hypothesis with a heuristic function in our experiment. In particular, a violation of this equidistribution hypothesis would provide a yardstick against which to assess the possible desirability of some shelf locations in terms of likelihood of item picking up.

\section{METHODS}

\subsection{Participants}

At the beginning of 2011, a group of 600 students from the University of Sassari, were randomly selected from those passing by our experimental station set up in a special area of the Central University Library. After having provided

\footnotetext{
${ }^{2}$ For example limitations were placed upon the avatar's ability to select items in the virtual aisle based on the average length of the human arm.
} 
written informed consent to participate in the study, the subjects filled out a questionnaire requesting some personal socio-demographic data (age, gender and handedness). The anonymity of the subjects was ensured by assigning each one a personal sequential numeric identification code.

\subsection{Virtual Environment}

The experiment was carried out within a 3-D environment created by ActiveWorlds ${ }^{\circledR}$ technology. The virtual environment simulates the aisle of an actual store (see Fig. 1).

In order to increase the level of immersion in the virtual environment, during the experiment the subject wore a head- mounted display (HMD). Specifically, we used a binocular vision visor by Headplay ${ }^{\circledR}$ (Virtual Image Size: 52" diagonal at 6'; Field of View - FoV -: 34 degrees diagonal; display technology: $\mathrm{LCoS}$ with refresh rate up to $120 \mathrm{~Hz}$; resolution: $1280 \times 720$ ) (see Fig. 2, which depicts the experimental devices).

Each subject in the experiment was assigned an avatar with the same characteristics in terms of height and arm length in a manner proportionate to the virtual environment. Participation in the experiment took place in first person view and consisted in performing a task, described below, anywhere along the length of the virtual aisle.

Subjects interacted with the virtual environment through the mouse and the keyboard at the experimental station (see

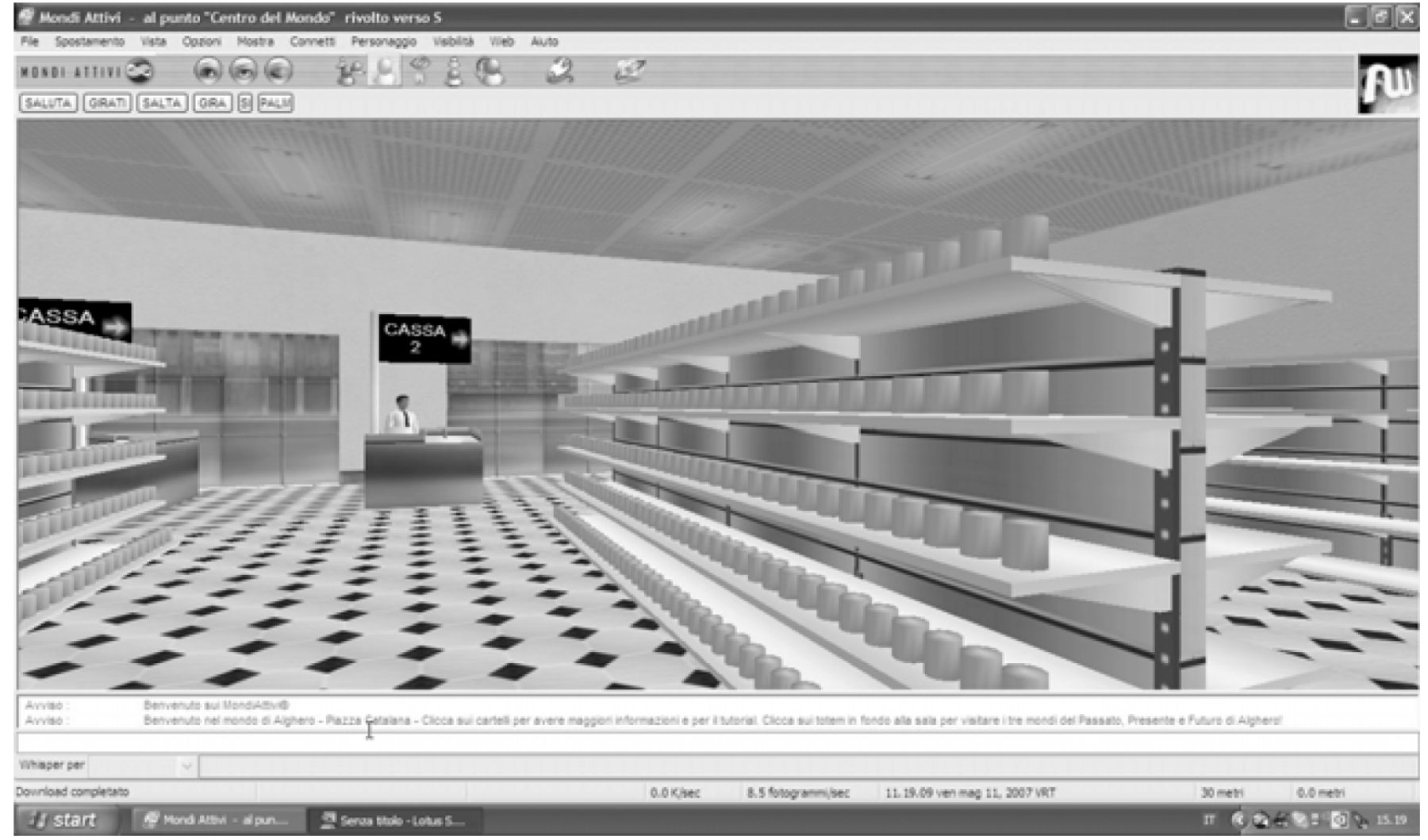

Fig. (1). The virtual aisle.

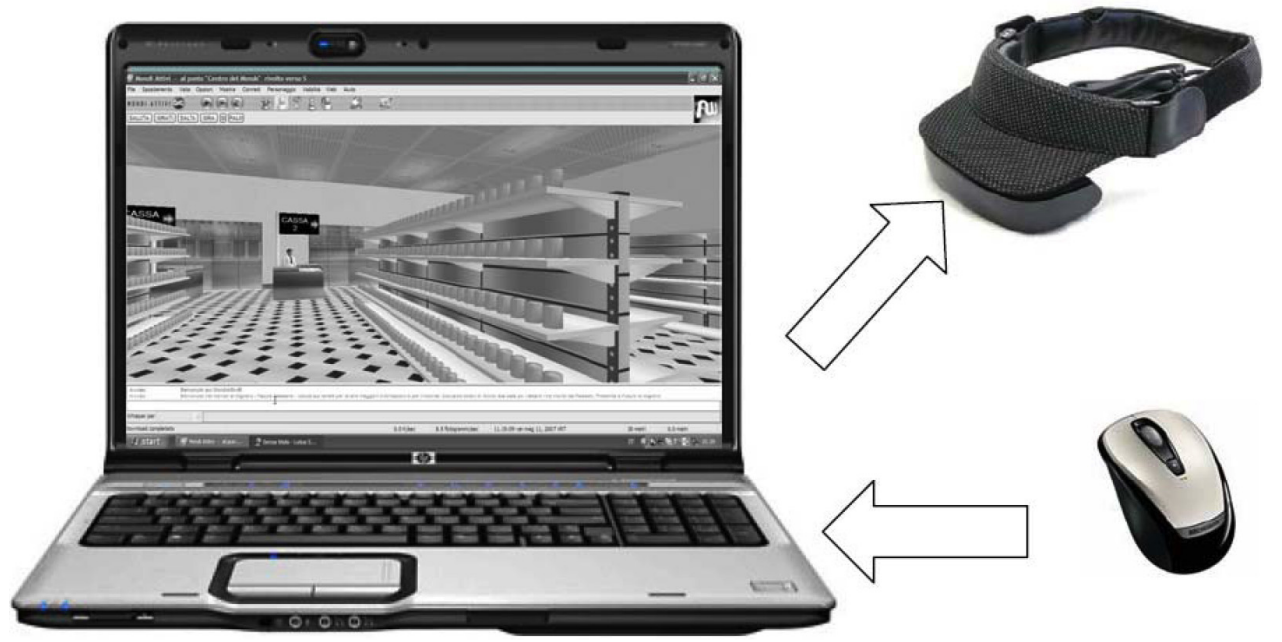

Fig. (2). Experimental devices. 
Fig. 2). Table 2 shows the subject's possible actions within the virtual aisle and the commands used to activate them.

Table 2. Commands and Corresponding Actions within the Virtual Aisle

\begin{tabular}{|c|c|}
\hline Command & Corresponding Action \\
\hline \hline Click of the mouse (left button) on one item & Picking up of the item \\
\hline ArrowUp & Forward \\
\hline ArrowDown & Back \\
\hline ArrowRight & Clockwise rotation \\
\hline ArrowLeft & Anticlockwise rotation \\
\hline Mouse forward/PagUp/Scroll mouse back & Look up \\
\hline Mouse back/PagDown/Scroll mouse fwd & Look down \\
\hline
\end{tabular}

The virtual environment is expressed on a scale of $1: 8$ with respect to reality when viewed at a distance of one meter. All measurements below are real and must be converted to $1: 8$ scale.

The virtual aisle was composed by two gondolas facing each other. The width of the lane was approximately 2.5 meters (the equivalent of approximately three flanked carts of average width). Each gondola contained 5 shelves and each shelf contained 39 facings. The distance between the shelves was uniform. The fourth shelf was placed at 1.50 meters above the floor.

Perfectly identical items belonging to an unspecified category were placed on the shelves. The items were represented by cylinders $(15 \mathrm{~cm}$ in diameter at the base and $15 \mathrm{~cm}$ in height) in shades of gray. The product brand was concealed. There was no indication of product type and price. No in-store promotion was simulated. In many respects, therefore, the experiment simulated a sort of blind conditions test used in order to prevent that the shelf position effect, if actually present, could somehow be biased by other phenomena. Burke [25, pp.128-129] explains some aspects of the problem when he states: "When making a purchase decision, consumers use certain cues to select among products. In some cases, the brand name and packaging are the critical stimuli. In other instances, price, shelf space, signage, smell, weight, taste, or texture may be important". Drèze et al., [5, p. 304] also note that: "The retailing environment is very noisy, with hundreds of competing stimuli vying for attention".

The results of our work could have been altered by a series of effects typical of a real purchasing situations that were instead kept under control in our experimental design (see Table 3).

\subsection{Procedure and Task}

Each subject received instructions by the same supervisor about the characteristics and capabilities of the platform used in the experiment and carried out a test run geared towards establishing familiarity with the virtual environment and with the commands used to move around it, as listed in Table 2. The test run was instrumental in mitigating the risks of initialization effects $[25,29,39]$.

The subject began the actual experiment standing one meter from the entrance to the aisle in a central position (in this way even items located at the beginning of virtual gondolas were within the FoV of the subject).

Initially, the subject faced the vanishing point of the virtual aisle and could then freely choose his/her direction and pace of progress along the lane. The avatar also had the capacity to step back.

The subject's task consisted in picking up only one of the items in the virtual aisle. Picking up an item was accomplished by going closer to the shelf, at arm's length, setting the mouse pointer on the item and clicking the left button. Each subject performed the test without knowing

Table 3. Some Effects Kept Under Control in the Experiment

\begin{tabular}{|c|c|}
\hline $\begin{array}{c}\text { Space allocation effect (Chandon et al., [21]; Nierop et al., [2]; } \\
\text { Chung et al., [17]; Drèze } \text { et al., [5]; Folwell and Moberg [18]; } \\
\text { Frank and Massy [23]. }\end{array}$ & Because of the anonymity of the items' packaging, each product had a single facing \\
\hline $\begin{array}{l}\text { Price effect (Chandon et al., [21]; Nierop et al., [2]; } \\
\text { Chung et al., [17]; Drèze et al., [5]). }\end{array}$ & The price of each item is hidden. \\
\hline $\begin{array}{l}\text { Type of good (Drèze et al., [5]; Folwell and Moberg [18]; } \\
\text { Frank and Massy [23]; Brown and Tucker [35]). }\end{array}$ & The nature of the product is concealed. \\
\hline $\begin{array}{l}\text { Brand effect (Nierop et al., [2]; } \\
\text { Drèze } \text { et al., [5]; Frank and Massy [23]). }\end{array}$ & The brand is hidden. \\
\hline Color, shape and size effect (Porcheddu et al., [36]) & All items are identical in term of color, shape and size of package. \\
\hline $\begin{array}{l}\text { Perceived display incompleteness-effect } \\
\quad \text { (Razzouck et al., [37]; Lugli [38]). }\end{array}$ & $\begin{array}{l}\text { The gondolas are always fully stocked when the subject begins the experiment } \\
\text { (he/she cannot infer the picking up choices of previous participants). }\end{array}$ \\
\hline
\end{tabular}


(and without being able to infer) the choices of those who preceded him/her.

\subsection{Statistical Methods}

Each of the two virtual gondolas was analytically expressed in the form of a matrix $\mathrm{S} \times \mathrm{F}$, which we termed "matrix of picking up frequencies" (MPUFs) (see Expression 1). $\mathrm{S}$ is the number of shelves of the virtual gondola (so $\mathrm{S}=$ $1, \ldots, 5)$, while $\mathrm{F}$ is the number of facings that make up the entire length of each shelf (so, $F=1, \ldots ., 39$ ). Overall, the MPUFs consists of 195 cells. Each matrix cell corresponds to an item, and whenever the item is removed, the system counts a frequency of the cell.

MPUFs $=\left[\begin{array}{cccc}\mathrm{sp}_{5,1} & \mathrm{sp}_{5,2} & \ldots & \mathrm{sp}_{5,39} \\ \ldots & \ldots & \ldots & \ldots \\ \mathrm{sp}_{2,1} & \mathrm{sp}_{2,2} & \ldots & \mathrm{sp}_{2,39} \\ \mathrm{sp}_{1,1} & \mathrm{sp}_{1,2} & \ldots & \mathrm{sp}_{1,39}\end{array}\right]$

Although two virtual gondolas facing down the aisle were designed, a single MPUFs was obtained by accumulating the picking up frequencies (PUFs) from both the right and left shelves according to a mirror-logic. In this way, our design took into account (and counteracted) the possible confounding variable of handedness, which might lead right-handed subjects to tend towards withdrawing items from the shelf on their right and left-handed subjects from gravitating towards the shelf on the left [40]. Thanks to this control, subjects were able to participate in the experiment regardless of their handedness.

We then conducted a goodness-of-fit test to evaluate whether the distribution of the observed PUFs conformed to the theoretical distribution of the expected frequencies generated under the assumption of random distribution of picking up choices in the different shelf locations. In particular, we ran a Chi-square goodness-of-fit test for a single sample to determine if the distribution of data in the sample was consistent or inconsistent with the hypothesized theoretical discrete uniform distribution of the population.

Finally, we arranged for a standardized residuals-based post-hoc analysis in the event of a significant Chi-square test.

\section{RESULTS}

\subsection{Descriptive Statistics}

600 subjects (306 female and 294 male; 541 right-handed and 59 left-handed) with total mean age of 23.43 years $(\mathrm{SD}=3.18)$ were admitted to the experiment.

Fig. (3) visually represents the PUFs observed in our experiment in an isometric chart in which the highest PUFs are found in the innermost areas, while the lowest PUFs are located in the outer areas.

A summary of the observed PUFs follows in Table 4 (the expected frequencies under the random-distribution hypothesis are indicated in parentheses).

Table 4. Observed PUFs (Expressed in \%) Associated with Various Areas of the Gondola (Expected PUFs, in $\%$, Shown in Parentheses)

\begin{tabular}{|l|l|}
\hline \multicolumn{1}{|c|}{ Section of the Gondola } & \multicolumn{1}{|c|}{ Observed PUF } \\
\hline \hline Vertical Dimension & $2(20)$ \\
Top level & $48(20)$ \\
Eye level & $45(20)$ \\
Waist level & $2(20)$ \\
Knee level & $3(20)$ \\
Floor level & \\
\hline Horizontal Dimension & $55(33.33)$ \\
First section of the gondola & $36(33.33)$ \\
Center section of the gondola & $9(33.33)$ \\
End section of the gondola & \\
\hline
\end{tabular}

An analysis of Table $\mathbf{4}$ reveals that certain sections of the gondola were associated with higher PUFs than was expected. Specifically, this is especially true: 1) along the vertical dimension at waist-level and eye-level and 2) along the horizontal dimension, starting at the first section of the gondola and continuing along its central section.

Moreover, specific shelf locations within these areas of the gondola were associated with a particularly strong gravitational force. This was most notable for the shelf position indicated by the letter A in Fig. (3) (facing no. 5 of

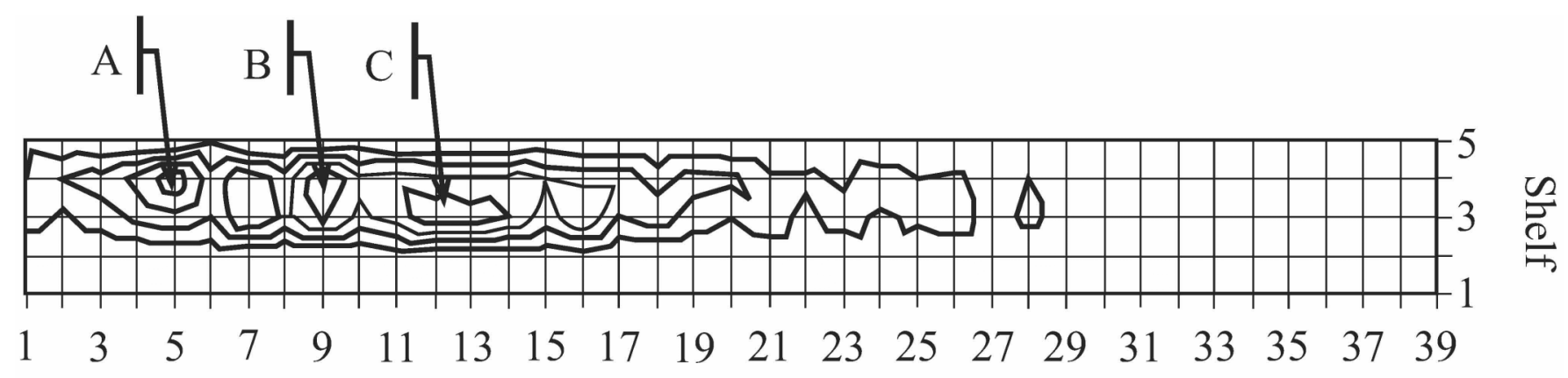

Facing

\author{
PUFs: $\square 0-4$ (most external area); $\square 5-8 ; \square 9-12 ; \square 13-16 ; \square \geq 17$ (innermost areas)
}

Fig. (3). Isometric representation of observed PUFs. 
the shelf at eye-level, with a $3.2 \%$ PUF); the vertically contiguous shelf locations marked by letter B in Fig. (3) (respectively facing no. 9 on the shelf at eye level, with an observed $3.3 \%$ PUF, and no. 9 on the shelf at waist level, associated with a $2.8 \%$ PUF); and the horizontally contiguous shelf locations marked by the letter $\mathrm{C}$ in Fig. (3) (facings nos. 12 and 13 on the shelf at waist level, which were associated with PUFs of $3.1 \%$ and $3 \%$ respectively). It must be noted that all expected PUFs for the above described shelf locations were $5.1 \%$.

By observing the distribution of observed PUFs, we can easily gauge the associated vertical and horizontal shelf position effects, both individual and joint. Let us first consider the vertical shelf location effect. At the same horizontal position (indicated by Facing*), the effects of shifting from a certain initial vertical shelf position (which we could call sphelf-start,Facing*) to another (which we could call $\mathrm{sp}_{\text {Shelf-arrive,Facing*) }}$ can be calculated in percentage terms by Expression 2.

(PUF $\mathrm{sp}_{\text {Shelf-arrive,Facing* }}$ - PUF $\mathrm{sp}_{\text {Shelf-start,Facing*)/PUF }} \mathrm{sp}_{\text {Shelf-start,Facing* }}$

The horizontal shelf location effect can be measured in a similar manner. At the same vertical position (marked by Shelf*), the effects of shifting from a certain initial horizontal shelf position (which we could call $\mathrm{sp}_{\text {Shelf }}{ }^{*}$,Facingstart) to another (which we could call $\mathrm{sp}_{\text {Shelf*,Facing-arrive) }}$ can be evaluated in terms of percentage by Expression 3.

(PUF sp ${\text { Shel }{ }^{*} \text {,Facing-arrive }}$ PUF $\mathrm{sp}_{\text {Shelf*,Facing-start }}$ )/PUF $\mathrm{sp}_{\text {Shelf*,Facing-start }}$

The shelf position effect along both dimensions may instead be estimated through the Expression 4, as done in the previous case.

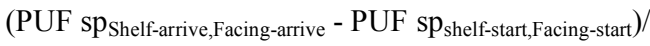

PUF $\mathrm{sp}_{\text {shelf-start,Facing-start }}$

Clearly, all the above formulas are applicable only in cases in which the observed PUFs associated with starting positions are different from zero.

\subsection{Chi-Square Goodness-of-Fit Test on Picking-Up Frequencies (PUFs)}

A Chi-square test of the null hypothesis that the shelf positions were equally attractive to the shoppers showed significance beyond the 0.001 level: $\chi^{2}(194)=1486.5$; asymptotic $p<0.001$.

Although some studies [41] have demonstrated that when a chi-square goodness-of-fit test is employed to evaluate a hypothesis regarding a uniform distribution the test is extremely robust, we also ran a Monte Carlo analysis.
Our data set was too large to calculate the exact $p$ value and we did not satisfy the assumptions necessary for employing the asymptotic method. In fact, each cell of the MPUFs had an expected frequency smaller than 5 [42]. In this situation, the Monte Carlo method provides an unbiased estimate of the exact $p$ value without the requirements of the asymptotic method. The Monte Carlo estimate of the $p$ value is 0.000 , and the $99 \%$ confidence interval with a Monte Carlo sample of 100,000 is $(0.000 ; 0.000)$.

We also conducted a post-hoc analysis using standardized residuals (SRs) to determine what cells/shelf positions were major contributors to rejecting the null hypothesis of the random-distribution of the PUFs. SRs beyond \pm 1.96 indicate a significant deviation at the .05 level from the expected values [43]. Given that we did not record SRs $<-1.96$, in Fig. (4) we provide an isometric chart of SRs with a cut-off value set at +1.96 .

One can easily see that the cells/shelf locations with statistically greater than expected frequencies were all at eye-level and waist-level/mid shelf. In addition, we stress that the shelf locations with SRs $>+1.96$ were concentrated almost exclusively in the first half of the gondola $(91 \%$ of recorded cases) along the hypothesized direction of traffic flow in the aisle.

\section{DISCUSSION}

The statistical analysis we carried out led us to reject the hypothesis of random distribution of PUFs with a high level of significance. Some shelf locations show a high gravitational force in terms of PUFs.

Our experiment conducted in a virtual aisle has highlighted the existence of significant vertical and horizontal shelf position effects.

A straightforward quantitative comparison of our data with results from previous studies is not realistic because of the heterogeneity of approaches (as previously stated, this also made a meta-analysis of the reviewed literature impossible to conduct). The study by Chandon et al., [21], for example, has indeed recently shown that analyses of shelf position effects are partially outcome dependent. Strictly speaking, therefore, our results should be compared directly with those of studies that have chosen PUF as a primary dependent variable. The only work in our literature review to use PUF in this manner is the study by Christenfeld [20]. Chandon et al., [21], however, also demonstrated the existence of some degree of positive correlation between results obtained by looking at different dependent variables related to shelf location effects measurement. In light of

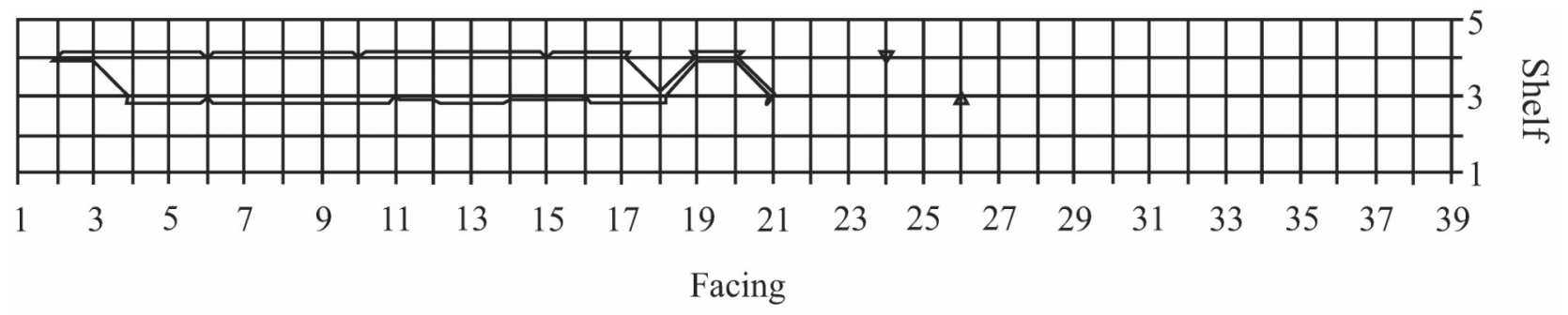

SRs: most external areas $\leq 1.96$; innermost areas $>1.96$

Fig. (4). Isometric representation of SRs. 
these premises, we shall discuss the results of our work within the framework of previous literature on the subject.

With regard to the vertical dimension, our work showed that the most desirable shelf positions are both at eye-level (this result is consistent with what is argued by Colonial Study [10, 11]; Hubbard [8]; Folwell and Moberg [18]; Drèze et al., [5]; Chung et al., [17]; Nierop et al., [2]; Chandon et al., [21]) and at waist-level (as previously found by Folwell and Moberg [18]; Christenfeld [20]; Chandon et al., [21]; Valenzuela and Raghubir $[22,24])$.

With regard to the horizontal dimension, our work showed that the most desirable shelf location is the first half of the gondola, along the hypothesized direction of traffic flow in aisle. In particular, the best horizontal shelf positions are those at the beginning of the gondola (also see Nierop et al., [2]) and by the first half of the central part of the gondola (this result is consistent with data obtained by Chandon et al., [21]; Valenzuela and Raghubir [19, 24]).

We therefore observe that our results are largely aligned with data reported in a substantial part of the existing literature.

Have we learned something new that was not previously documented in the existing literature? We shall discuss this in light of two main knowledge gaps that our study endeavored to fill (see the above-illustrated Section 3 ).

First, the overall consistency of our results with part of the existing literature on shelf-position effects is somewhat surprising given that our results were obtained in an experimental context in which a number of potentially confounding variables were inhibited. This suggests that the variables kept under control in our study may be relatively non-influential in real contexts and do not significantly distort the analysis of shelf position effects. Paraphrasing Drèze et al., [5, p.304], the actual retailing environment is probably not too "noisy" for a shelf position effects analysis.

Second, we argue that our results possibly also give our study discriminant power with respect to the validity of the theories underlying the literature on shelf position effects. As discussed earlier, three different theoretical approaches can be identified in the literature: attention-based, belief-based, and physical or mental effort-minimization based. Since in our simulation we did not reproduce the physical effort associated with item selection in the real world (similarly to previous studies such as Massara and Pelloso [44]; Campo et al., [29]; Burke et al., [26]), clearly our subjects were not in a position of having to minimize this type of effort. The fact that, in line with previous works that made reference to the minimal-physical effort Theory (Colonial Study [10, 11]), our work demonstrated the robustness of centrality preference (on the vertical plane and, at least in part, on the horizontal plane as well), leads us to believe that this theory does not provide a satisfactory explanation for shelf position effects, at least when considered in isolation. Unfortunately, though our study appears to expose the weakness of the minimal-physical effort principle, it does not clarify whether the clustering of PUFs in certain shelf locations is due to the attentional salience of these positions or to some shelf location-related beliefs shared by most of the shoppers. Moreover, strictly speaking, our experiment also does not provide sufficient evidence to contradict the possible validity of explanations based on minimal-mental effort theory.

\section{LIMITATIONS OF THE EXPERIMENT}

One possible limitation of the study is the oversimplification of the characteristics and operation of the virtual environment we utilized and the potential implications of this lack of realism upon the external validity of the results.

The differences between the context we created and an actual shopping experience are indeed numerous and quite significant (for instance, nearly total absence of physical effort associated with item selection, identical appearance of items in the virtual space, etc.). However, it is important not to fall into the trap of thinking that a more realistic experiment necessarily leads to more generalizable results [33].

Although the generalizability of the results is in fact not an intrinsic characteristic of simulations, as discussed above our experiment showed a clear convergence between the results we obtained and a considerable portion of empirical data found in the existing literature. This consistency of results is, in a sense, an ipso facto statement about the external validity of the simulation that we conducted [45, 46].

This being said, however, the generalizability of our results is affected by our ability to (deliberately or inadvertently) deal with the background factors mentioned by Lynch [33]. One can therefore conclude that the reach of our results is limited to the subset of factors that can influence the analyzed behavior (the selection of items in a virtual aisle) which we were able to take into account (more or less deliberately). In particular, our simulation cannot exclude a priori the possible role of shelf position-based beliefs.

This underscores the main limitation of our experiment, which, while it allowed us to surmise that physical effort factors do not seem to be a good explanation for shelf position effects, failed to clarify the possible role played by the subjects' beliefs. In short, our results are unable to discriminate between attention-based and belief-based effects. Strictly speaking, as mentioned above, even explanations based on minimal-mental effort theory could not be excluded.

\section{MANAGERIAL IMPLICATIONS}

The results of our study create a map of the quality of the gondola space. This map, obtained by normalizing or inhibiting a number of hypothesized confounding variables, shows the inherent nature of the qualitative characteristics of certain shelf positions. The convergence of simulation results and existing empirical data indeed seems to point out that the magnitude of the shelf position effects is significant, and would not be distorted by the presence of a number of potential interfering variables in a physically real shopping situation (at least those variables within the subset considered in our study).

In our opinion, this article has some managerial implications both for retailers and manufacturers. In particular, with regard to retailers, our analysis provides information about the more 
desirable locations on the in-aisle gondola. These results are clearly useful for merchandisers who, within a complex framework of constraints, deal with space-allocation issues and are concerned with the quality of shelf-space for displaying different product categories and brands in order to achieve the objectives of merchandising.

Conversely, our study is also of some interest for manufacturers who are willing to pay significant premiums and are in competition with each other to obtain the preferred item display locations, rather than vying for additional quantities of shelf-space.

A mapped out depiction of the more desirable shelf locations can provide a significant base of information during the negotiation phase for the settlement of slotting fees that are charged to manufacturers by retailers to keep existing items on their shelves or to display new ones.

\section{ETHICAL ASPECTS}

Approval by the local Committee on Bioethics, though requested, was not required for this study because the research involved only healthy subjects and non-invasive testing procedures. The subjects, all students at the University of Sassari, signed an informed consent form for participation in the experiment, which was therefore voluntary. No compensation whatsoever was offered to the participants.

\section{NOTES ON CONTRIBUTORS}

Daniele Porcheddu is an Assistant
Professor in the Department of
Economics, Business and Regulation
at the University of Sassari (Italy),
where he got a PhD in Management
Sciences. His research interests
include merchandising and retail
regulation.

Alberto Venturi is a Researcher in
the Electronic and Electrical
Engineering Department at the
Strathclyde University of Glasgow
(UK). He received a degree from the
Polytechnic University of Milan
(Italy). His research deals with
system modeling and model order
reduction.

\section{ACKNOWLEDGEMENTS}

The authors thank the Editor and the two anonymous Referees for their helpful comments on a previous version of this article. They also thank Myriam D'Assunta, Luca Ferrucci, and Gianpiero Lugli for their valuable suggestions.

\section{REFERENCES}

[1] Hübner AH, Kuhn H. Retail category management: State-of-the-art review of quantitative research and software applications in assortment and shelf space management. Omega 2012; 40: 199209.

[2] Nierop E, Fok D, Franses PhH. Interaction between shelf layout and marketing effectiveness and its impact on optimizing shelf arrangements. Mark Sci 2008; 27: 1065-82.
[3] Campo K, Gijsbrechts E. Retail assortment, shelf and stockout management: Issues, interplay and future challenges. Appl Stoc Mod Bus Ind 2005; 21: 383-92.

[4] Desmet P, Renaudin V. Estimation of product category sales responsiveness to shelf-space allocated. Int J Res Mark 1998; 15: 443-57.

[5] Drèze X, Hoch SJ, Purk ME. Shelf Manage Space Elasticity. J Retail 1994; 70: 301-26.

[6] D'Amico MF, Hawes JM, Lewison DM. Management perception of the sales effects of shelf space and position. J Food Products Mark 1993; 1: 13-22.

[7] Phillips HC, Bradshaw RP. How customers actually shop: customer interaction with the point of sale. J Mark Res Soc 1993; 35: 51- 63.

[8] Hubbard CW. The "shelving" of increased sales. J Retail 19691970; 45: 75-84

[9] Masson JE, Wellhoff A. Le merchandising. Paris, Dunod 2003.

[10] The Colonial Study. Progressive Grocer 1963; 42(9).

[11] The Colonial Study. Progressive Grocer 1964; 43(3).

[12] Breugelmans E, Campo K, Gijsbrechts E. Shelf sequence and proximity effects on online grocery choices. Mark Lett 2007; 18: 117-33.

[13] Burgoyne DG, Johnston CB. Are shelf space and shelf location really important? Bus Quart 1968; 33: 56-60.

[14] Curhan RC. The effects of merchandising and temporary promotional activities on the sales of fresh fruit and vegetables in supermarkets. J Mark Res 1974; 11: 286-94.

[15] Chevalier M. Increase in sales due to in-store display. J Mark Res 1975; 12: 426-31.

[16] Wilkinson JB, Mason JB, Paksoy CH. Assessing the impact of short-term supermarket strategy variables. J Mark Res 1982; 19: 72-86.

[17] Chung C, Schmit TM, Dong D, Kaiser HM. Economic evaluation of shelf-space management in grocery stores. Agribusiness 2007; 23: 583-97.

[18] Folwell RJ, Moberg DA. Factors in retail shelf management impacting wine sales. Agribusiness 1993; 9: 595-603.

[19] Valenzuela A, Raghubir P. Position-Based Beliefs: The CenterStage Effect. J Cons Psychol 2009; 19: 185-96.

[20] Christenfeld N. Choices from identical options. Psychol Sci 1995; 6: 50-5.

[21] Chandon P, Hutchinson JW, Bradlow ET, Young SH. Does InStore Marketing Work? Effects of the Number and position of shelf facings on attention and evaluation at the point of purchase. J Mark 2009; 73: 1-17.

[22] Valenzuela A, Raghubir P. Are Top-bottom inferences conscious and left-right inferences automatic? implications for shelf space positions. Working paper 2009.

[23] Frank RE, Massy WF. Shelf position and space effects on sales. J Marketing Res 1970; 7: 59-66.

[24] Valenzuela A, Raghubir P. Product "position"-ing: implications of vertical and horizontal shelf space placement. Adv Cons Res 2009; 8: 22-3.

[25] Burke RR. Virtual Shopping: Breakthrough in Marketing Research. Harvard Bus Rev 1996; 74: 120-31.

[26] Burke RR, Bari AH, Kahn BE, Lodish LM. Comparing dynamic consumer choice in real and computer-simulated environments. J Cons Res 1992; 19: 71-82.

[27] Bell GH, Ledolter J, Swersey AJ. A plackett-burman experiment to increase supermarket sales of a national magazine. Interfaces 2009; 39: $145-58$.

[28] Cunningham AC, O'Connor NJ. Consumer reaction to retail price and display changes. Br J Mark 1968; 2: 147-51.

[29] Campo K, Gijsbrechts E, Guerra F. Computer simulated shopping experiments for analyzing dynamic purchasing patterns: validation and guidelines. J Empir Generalisations Mark Sci 1999; 4: 22-61.

[30] Sawyer AG, Worthing PM, Sendak PE. The role of laboratory experiments to test marketing strategies. J Mark 1979; 43: 60-7.

[31] Nevin JR. Laboratory experiments for estimating consumer demand: A Validation Study. J Mark Res 1974; 11: 261-8.

[32] Gabor A, Granger CWJ, Sowter AP. Real and hypothetical shop situations in market research. J Mark Res 1970; 7: 355-9.

[33] Lynch JG Jr. On the external validity of experiments in consumer research. J Cons Res 1982; 9: 225-39.

[34] Buttle F. Merchandising. Eur J Mark 1984; 18: 104-25.

[35] Brown W, Tucker W. The marketing center: vanishing shelf space. Atlanta Econ Rev 1961; 9: 9-13. 
[36] Porcheddu D, Usai A, Venturi A. Nonverbal stimuli in a virtual aisle: does the shelf you choose matter?, Int Rev Retail Distrib Cons Res 2011; 21:215-31.

[37] Razzouk NY, Seitz V, Kumar V. The impact of perceived display completeness/incompleteness on shoppers' in-store selection of merchandise: an empirical study. J Retail Cons Services 2002; 9: $31-5$.

[38] Lugli G. Neuroshopping. Milan, Apogeo 2010.

[39] Cohen S, Gadd M. Virtual reality shopping simulation for the modern marketer. Mark Res Today 1996; 24: 18-26.

[40] Underhill P. Why we buy: the science of shopping. New York, Simon \& Schuster 1999.
[41] Zar JH. Biostatistical analysis $4^{\text {th }}$ ed. Upper Saddle River, NJ. Prentice Hall 1999.

[42] Siegel S, Castellan NJ. Nonparametric statistics for the behavioral sciences $2^{\text {nd }}$ ed. New York, McGraw-Hill Book Company 1988.

[43] Sheskin DJ. Handbook of Parametric and Nonparametric Statistical Procedures $3^{\text {rd }}$ ed. Boca Raton, FL, Chapman\&Hall/CRC 2004.

[44] Massara F, Pelloso G. Investigating the Consumer-Environment Interaction Through Image Modelling Technologies. Int Rev Retail Distrib Cons Res 2006; 16: 519-31.

[45] Garson GD. Computerized Simulation in the Social Sciences. Simulation \& Gaming 2009; 40: 267-79.

[46] Davis JP, Eisenhardt KM, Bingham CB. Developing Theory Through Simulation Methods. Acad Manag Rev 2007; 32: 480-99.

(C) Porcheddu and Venturi; Licensee Bentham Open.

This is an open access article licensed under the terms of the Creative Commons Attribution Non-Commercial License (http://creativecommons.org/licenses/by$\mathrm{nc} / 3.0 /$ ) which permits unrestricted, non-commercial use, distribution and reproduction in any medium, provided the work is properly cited. 